\title{
Dynamic compressive and splitting tensile properties of concrete containing recycled tyre rubber under high strain rates
}

\author{
GUO YANG ${ }^{1,2}$, XUDONG CHEN $^{1,2, * \mathbb{D}}$, WEIHONG XUAN ${ }^{3}$ and YUZHI $\mathrm{CHEN}^{3}$ \\ ${ }^{1}$ State Key Laboratory of Water Resources and Hydropower Engineering Science, Wuhan University, \\ Wuhan 430072, People's Republic of China \\ ${ }^{2}$ College of Civil and Transportation Engineering, Hohai University, Nanjing 210098, People's Republic of \\ China \\ ${ }^{3}$ Jinling Institute of Technology, Architectural Engineering Institute, Nanjing 211169, People's Republic of \\ China \\ e-mail: yangguoneo@hotmail.com; cxdong1985@hotmail.com
}

MS received 31 October 2017; revised 26 March 2018; accepted 2 May 2018; published online 20 September 2018

\begin{abstract}
In order to raise the efficiency of resource utilization, recycling waste rubber particles into concrete as aggregate has been widely accepted. When the size and content of the rubber particles are appropriate, rubberized concrete can achieve many excellent properties. This study investigated the impact of rubber replacement on dynamic compressive and splitting tensile properties of concrete. The split Hopkinson pressure bar tests of rubberized concrete containing 5\%, 10\%, 15\% and $20 \%$ volume replacement for sand were completed. The failure modes, stress curves and dynamic strength values of rubberized concrete under high strain rates were recorded. The results reveal that the dynamic compressive and splitting tensile strength of rubberized concrete decrease with increasing rubber content. Meanwhile, peak strain increases with increasing rubber content. Dynamic increase factors (DIFs) of compressive and splitting tensile strength also were calculated, where rubberized concrete shows a stronger strain rate sensitivity. The analysis of specific energy absorption illustrates that rubberized concrete with $15 \%$ rubber replacement has the best impact toughness. In addition, ratios of dynamic compressive-tensile strength of rubberized concrete were calculated, which are between 3.82 and 5.39.
\end{abstract}

Keywords. Rubberized concrete; impact behaviour; high strain rates; energy absorption; split Hopkinson pressure bar.

\section{Introduction}

Nowadays, recycling waste products to reduce environmental pollution has become a consensus of the whole society. Due to the rapid growth of the use of rubber tyre, a large number of rubber wastes are generated every year. Landfill or incineration of rubber is not only a serious environmental pollution but also a waste of resources. Therefore, recycling waste rubber as fine or coarse aggregates into concrete has been currently researched.

Compared with ground, shredded or chipped rubber, more researchers use crumb rubber (about $1-5 \mathrm{~mm}$ ) to replace natural sand to obtain rubberized concrete [1-3]. It has been well documented that the compressive and splitting tensile strength of rubberized concrete dramatically decrease with increasing rubber content, while the effect of the size of crumb rubber (within the $1-5 \mathrm{~mm}$ range) on mechanical behaviour is small $[4,5]$. When the size and

*For correspondence content of the rubber particles are appropriate, rubberized concrete can achieve many excellent properties, such as toughness, ductility [6], thermal and acoustic properties [3]. In addition, adding rubber can enable achieving a low density and a high resistance to fatigue [7], abrasion, shrinkage [8], acid attack, penetration [9] and freeze-thaw cycles [10]. These excellent properties make the loss of strength worthwhile.

The excellent behavior of rubberized concrete makes it a promising material for civil and military applications, such as exterior walls of super high-rise building, highway sound walls, bridges, dams and nuclear power plants as well as primary and secondary containment shells $[1,11]$. Hence, it is important to investigate the behaviour of this material under impact. For example, super-high-rise buildings and bridges usually consider a plane impact; also, nuclear power plants and containment shells must take the impact of bomb explosion into account in their structural designs and numerical simulations. Many dynamic mechanical parameters of rubberized concrete at high strain rates are 
required. Split Hopkinson pressure bar (SHPB) test can yield enough information on various stages of concrete deterioration under high strain rate. This information will be very useful for the applications of rubberized concrete.

Impact behaviours of rubberized concrete have been studied by the drop weight test [12-16]. Experimental results revealed that the addition of rubber as substitution of aggregate dramatically increases impact behaviours and energy dissipation capacity. Some researchers [17, 18] used SHPB test to study the impact compressive properties of rubberized concrete under high strain rates, and obtained the same results. Long et al [19] focused on the impact compressive properties of self-compacting concrete containing rubber particles. Li et al [4] found that the dynamic compressive strength of recycled aggregate concrete incorporating rubber particles increased with the size, where the maximum dynamic compressive strength corresponded to size of $4.04 \mathrm{~mm}$.

However, limited attention has been paid to the dynamic tensile behaviour of rubberized concrete. Furthermore, the compressive properties at high strain rates should be further studied. These parameters are of critical importance for application of rubberized concrete. In this work, the dynamic compressive and splitting tensile properties of concrete containing different rubber contents were studied by SHPB tests. From the energy point of view, further analysis about impact resistance of rubberized concrete was carried out.

\section{Experimental program}

\subsection{Materials}

Ordinary Portland cement (P.O. 42.5), clean river sand $(G=2.60)$, coarse aggregate $(G=2.65)$ and supplied tap water were used, along with polycarboxylic superplasticizer, which was sourced from Sobute New Material Co. Ltd. in Nanjing, China. Properties of the cement are summarized in table 1. As shown in figure 1, rubber particles are in size of about $1-5 \mathrm{~mm}$ and sourced from Nanjing Jiexiang Sport Co. Ltd, China. Table 2 shows the characteristics of rubber particles. Figure 2 illustrates aggregate particle size distribution curves. To obtain a clean rubber surface, rubber particles were washed using clean tap water before tests.

\subsection{Mix proportions}

Table 3 shows the mix designs of rubberized concrete in this study. This mixture was designed with constant water and cement ratio of 0.45 . The sand was replaced by rubber particles with four volume replacements of 5\%, 10\%, 15\% and $20 \%$, which correspond to mix ID of RC5, RC10, RC15 and RC20, respectively. PC denotes plain concrete. Due to
Table 1. Properties of cement.

\begin{tabular}{lc}
\hline Characteristics & Results \\
\hline Chemical composition & \\
$\mathrm{SiO}_{2}$ & $24.4 \%$ \\
$\mathrm{Al}_{2} \mathrm{O}_{3}$ & $7.3 \%$ \\
$\mathrm{Fe}_{2} \mathrm{O}_{3}$ & $3.98 \%$ \\
$\mathrm{CaO}$ & $59.85 \%$ \\
$\mathrm{MgO}$ & $3.85 \%$ \\
$\mathrm{SO}_{3}$ & $2.5 \%$ \\
Physical properties & \\
Density & $3100 \mathrm{~kg} / \mathrm{m}^{3}$ \\
PH & 11.5 \\
Fineness modulus & 2.7 \\
Loss on ignition & $1.99 \%$ \\
Specific area & $367 \mathrm{~m}^{2} \mathrm{~kg}^{-1}$ \\
\hline
\end{tabular}

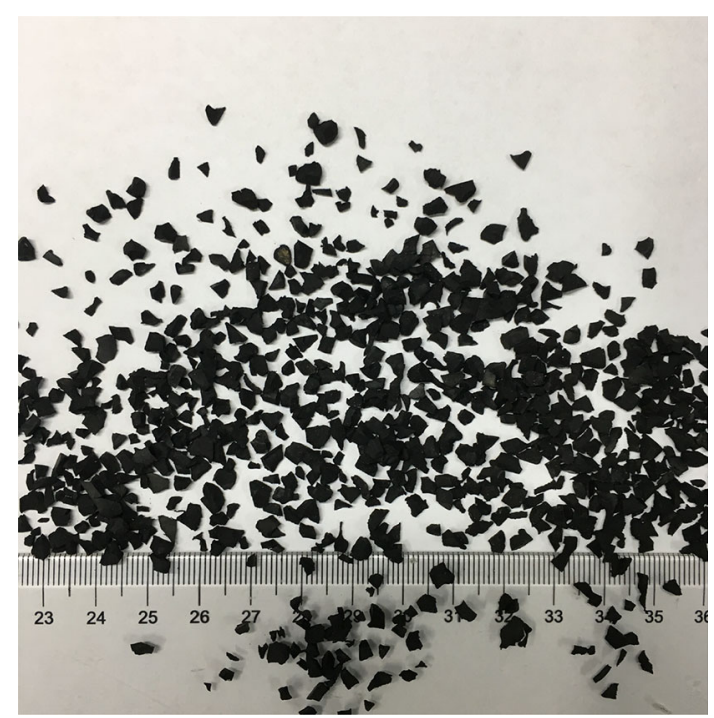

Figure 1. Rubber particles.

Table 2. Characteristics of rubber particles.

\begin{tabular}{lc}
\hline Characteristics & Results \\
\hline Ash content & $2.4 \%$ \\
Carbon black content & $18 \%$ \\
Density & $1060 \mathrm{~kg} / \mathrm{m}^{3}$ \\
Apparent density & $433 \mathrm{~kg} / \mathrm{m}^{3}$ \\
Tensile strength & $11 \mathrm{MPa}$ \\
\hline
\end{tabular}

low specific gravity, rubber particles tend to the surface layer of concrete. To avoid this problem, water-soaking treatment method [20] was used in this study. Due to the water-soaking treatment of $24 \mathrm{~h}$, air bubbles were released gradually and rubber hydrophobicity decreased. Samples 


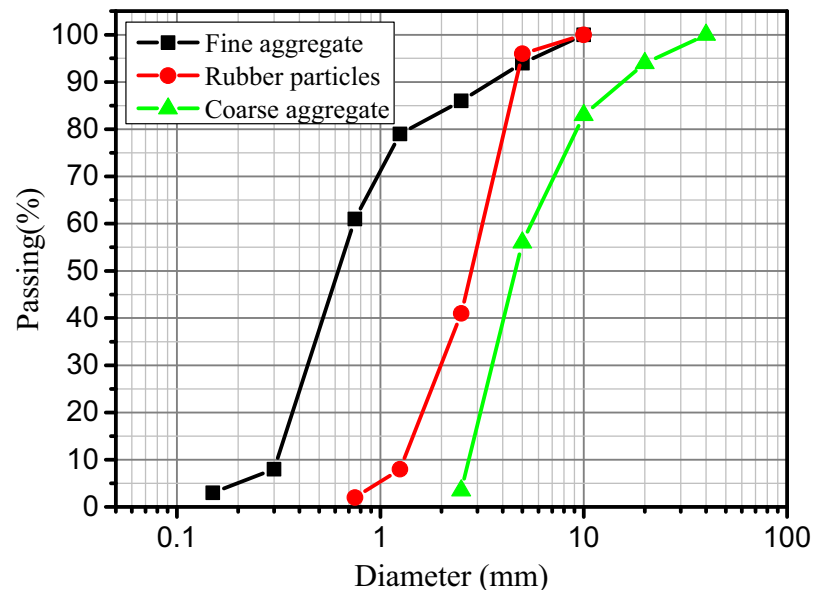

Figure 2. Aggregate particle size distribution curves.

were cut vertically to investigate vertical distribution of rubber particles. The cut surfaces (see figure 3) of the sample indicate that rubber particles can evenly disperse in the mix. Slump values were measured and the results are shown in table 3 . There is a slight reduction in slump values as the rubber content is raised. However, rubber content cannot significantly affect the workability of the concrete when the replacement of fine aggregate is less than $20 \%$. This phenomenon is in general agreement with previous studies [21]. Concrete cylinder specimens were prepared by casting concrete into PVC pipes with the height of $250 \mathrm{~mm}$ and the diameter of $74 \mathrm{~mm}$, which were closed by plates at one end. After curing in water for 28 days, some of them were then cut into $\varnothing 74 \times 148 \mathrm{~mm}^{2}$ Brazil disks as specimens. Others were cut into $\varnothing 74 \times 148 \mathrm{~mm}^{2}$ cylinders for quasi-statics compressive tests. Finally, both ends of these specimens were polished.

\subsection{Test methods}

2.3a Quasi-static tests: Quasi-static compressive and splitting tensile tests were carried out using an electro-hydraulic servo universal testing machine according to ASTM C39/ C39M-17b [22] and ASTM C496/C496M-11 [23], as shown in figures 4 and 5 .

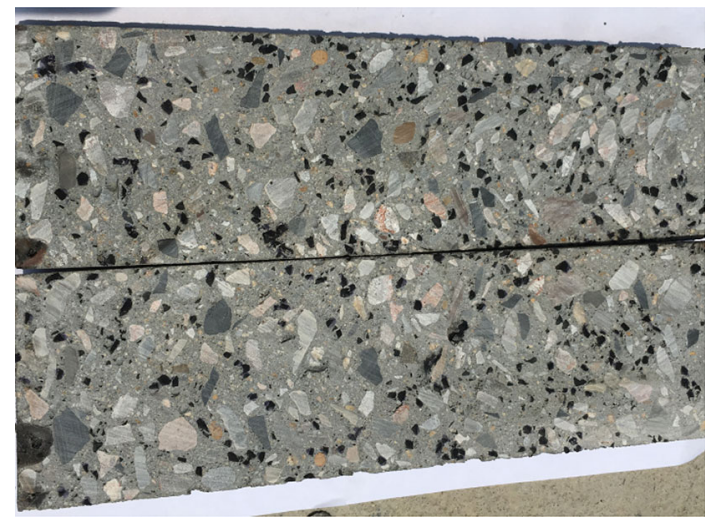

Figure 3. Cut surfaces of rubberized concrete.

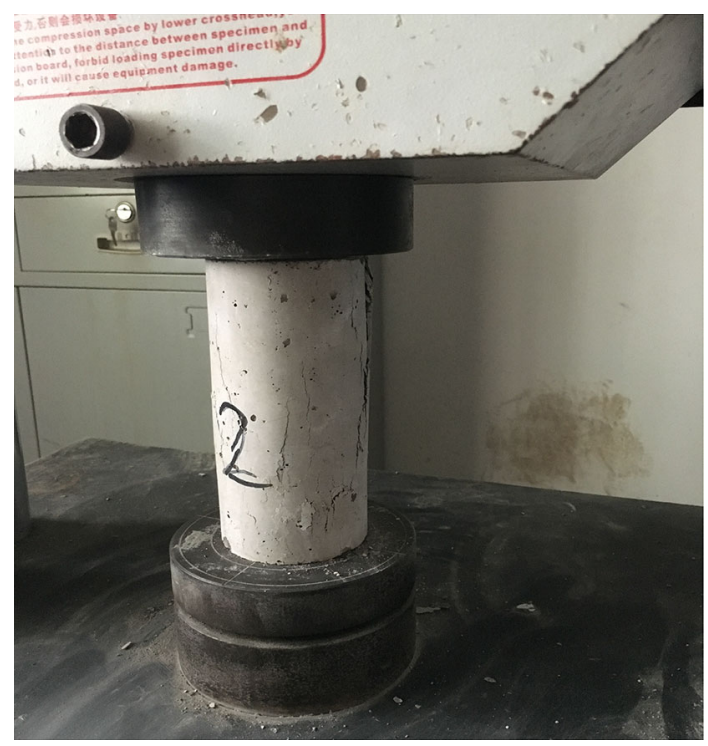

Figure 4. Loading method of quasi-static compression test.

2.3b SHPB tests: For this study, both the dynamic compressive and splitting tensile tests were completed using a SHPB system [24, 25]. The SHPB system consists of the pressure vessel, strike bar, incident bar, transmitted bar, data processing system, etc. An electronic counter was used to measure impact velocity. A copper pulse shaper was

Table 3. Concrete mix designs.

\begin{tabular}{lccccccc}
\hline $\begin{array}{l}\text { Mix ID } \\
\left(\mathrm{kg} / \mathrm{m}^{3}\right)\end{array}$ & $\begin{array}{c}\text { Water } \\
\left(\mathrm{kg} / \mathrm{m}^{3}\right)\end{array}$ & $\begin{array}{c}\text { Cement } \\
\left(\mathrm{kg} / \mathrm{m}^{3}\right)\end{array}$ & $\begin{array}{c}\text { Sand } \\
\left(\mathrm{kg} / \mathrm{m}^{3}\right)\end{array}$ & $\begin{array}{c}\text { Coarse aggregate } \\
\left(\mathrm{kg} / \mathrm{m}^{3}\right)\end{array}$ & $\begin{array}{c}\text { Rubber } \\
\left(\mathrm{kg} / \mathrm{m}^{3}\right)\end{array}$ & $\begin{array}{c}\text { Super-plasticizer } \\
\left(\mathrm{kg} / \mathrm{m}^{3}\right)\end{array}$ & $\begin{array}{c}\text { Slump value } \\
(\mathrm{mm})\end{array}$ \\
\hline PC & 171 & 380 & 819 & 1000 & 0 & 1.9 & 1.9 \\
RC5 & 171 & 380 & 778.05 & 1000 & 16.7 & 33.4 & 1.9 \\
RC10 & 171 & 380 & 737.1 & 1000 & 50.1 & 1.9 & 1.9 \\
RC15 & 171 & 380 & 696.15 & 1000 & 66.8 & 1.9 \\
RC20 & 171 & 380 & 655.2 & 1000 & & 136 \\
\hline
\end{tabular}




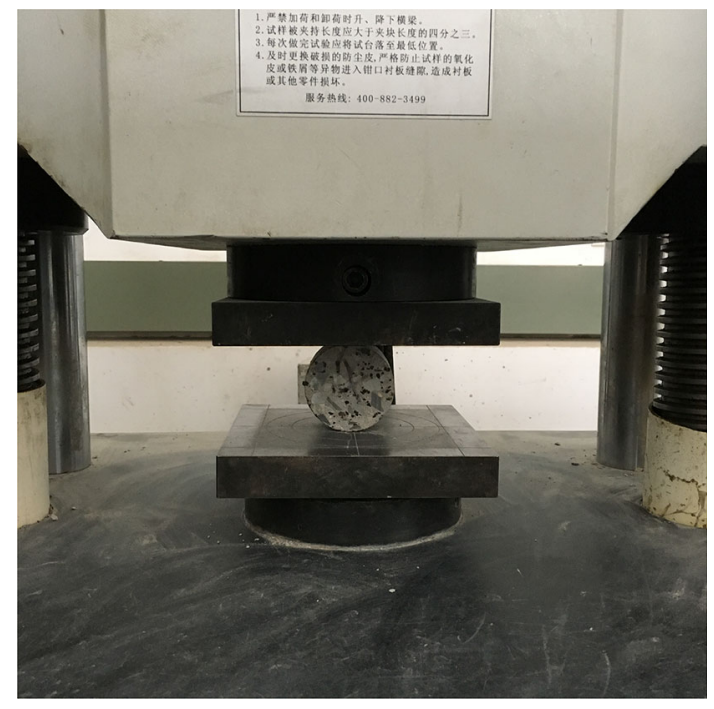

Figure 5. Loading method of quasi-static splitting tensile test.

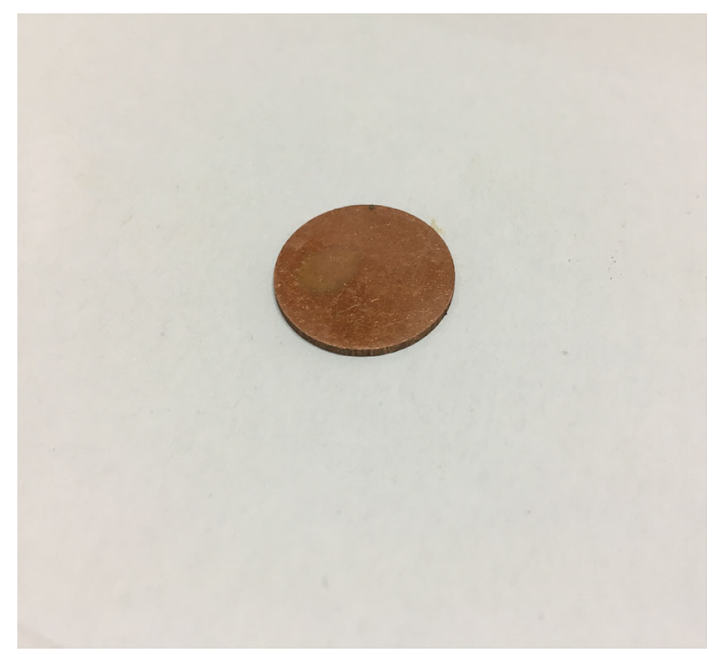

Figure 6. Pulse shaper.

utilized in tests to obtain a better waveform [26]. As shown in figure 6 , the diameter and thickness of the shaper are 20 and $1 \mathrm{~mm}$, respectively. A gimbal device was utilized in the dynamic compressive test to achieve a better contact between the bars and specimen (see figure 7). The diameters of specimens, the incident bar and transmitted bar are all $74 \mathrm{~mm}$ in this experiment. The diameter and length of the strike bar are 37 and $600 \mathrm{~mm}$, respectively. The specimens were placed between two bars using two different forms to accomplish the dynamic compressive and splitting tensile tests, respectively, as sketched in figures 8 and 9 .

The striker bar can be launched by a pressure vessel towards the incident bar, resulting in the generation of the incident stress pulse. Parts of the pulse are delivered by the specimen to the transmitted bar, and the rest is reflected back to the incident bar. The strain gauges can record the incident wave $\varepsilon_{i}(t)$, reflected wave $\varepsilon_{\mathrm{r}}(t)$ and transmitted wave $\varepsilon_{t}(t)$. The stress $\sigma(t)$, strain $\varepsilon(t)$ and strain rate $\dot{\varepsilon}(t)$ of concrete were determined utilizing the following formulas based on one-dimensional wave assumption [27]:

$$
\begin{gathered}
\sigma(t)=\left(E_{b} A_{b} / A_{s}\right) \varepsilon_{t}(t), \\
\varepsilon(t)=-\frac{2 C_{b}}{l_{s}} \int_{0}^{t} \varepsilon_{\mathrm{r}}(t) d t, \\
\dot{\varepsilon}(t)=-\frac{2 C_{b}}{l_{s}} \varepsilon_{\mathrm{r}}(t),
\end{gathered}
$$

where $E_{b}$ and $A_{b}$ denote the elastic modulus and crosssectional area of the transmitted bar, respectively, $A_{s}$ and $l_{s}$ denote the cross-sectional area and thickness of the specimens and $C_{b}$ denotes the longitudinal wave velocity of the bars.

Since the contact area between the bars and specimen is too small in the dynamic splitting tensile tests, strain results cannot be obtained accurately. This paper chooses the stress-time history curves to characterize dynamic splitting tensile properties of rubberized concrete. The impact air pressures of $0.15,0.3,0.45,0.6,0.75$ and $0.9 \mathrm{MPa}$ were chosen in the pre-test. At $0.15 \mathrm{MPa}$, there are no significant failure modes in impact compression test, though the specimens separate into two halves in dynamic splitting tensile tests. When air pressure is too high, it is harmful to achieve accurate data due to the instability of air pressure and strain gauge signal. In addition, the differences in failure modes also cannot be observed significantly. Above all, $0.3,0.45,0.6$ and $0.75 \mathrm{MPa}$ were chosen for the dynamic compression tests, and $0.15,0.3,0.45$ and 0.6 MPa were chosen for the dynamic splitting tensile tests.

\section{Results and discussion}

\subsection{Quasi-static tests}

There is a steady decrease in quasi-static compressive strength of the specimens with increased rubber replacement under the quasi-static loading, as shown in figure 10 . The largest decline has been in reducing by $33.63 \%$ at rubber replacement of $20 \%$. Three mechanisms can be responsible for this phenomenon. (a) Rubber particles have an extremely low modulus compared with hardened cement paste. As a result, rubber particles are in the concrete-like holes, and cannot resist external loads [11]. (b) Due to the poor bond between rubber particles with concrete, in the interfacial transition zone (ITZ) of rubber particles and concrete it is easy to generate stress concentration [28]. (c) Rubber has a tendency to entrap a large number of air bubbles to concrete resulting from the non-polar and rough surface of rubber particles in nature $[29,30]$. The increase of porosity leads to the reduction of strength. 


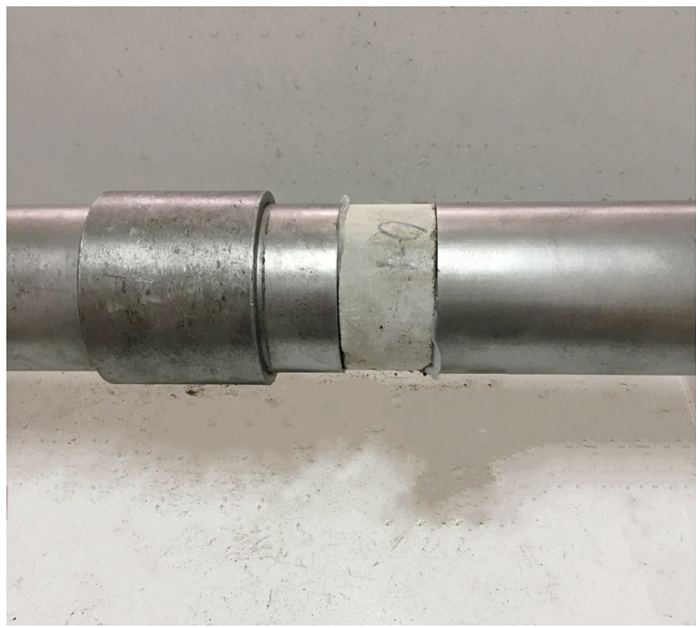

Figure 7. Gimbal device.

The impact of rubber content on quasi-static splitting tensile strength is presented in figure 11. Quasi-static splitting tensile strength reduces sharply at 5\% rubber replacement. However, the reduction is not significant at higher rubber replacement. Similar results were also found in previous experiments [2]. The poor bond between rubber particles and cement paste in tensile zone of concrete can lead to stress concentration. Meanwhile, rubber particles can also prevent the development of crack generated by stress concentration. Thus, when rubber content continues to increase, the splitting tensile strength of rubberized concrete cannot decrease multiply.

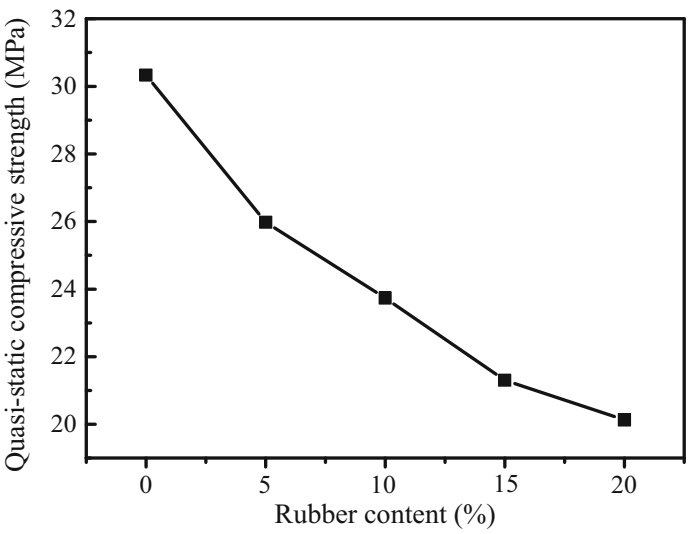

Figure 10. Quasi-static compressive strength of specimens with different rubber contents.

\subsection{Dynamic compressive tests}

3.2a Failure modes: The incorporation of rubber particles considerably improves the toughness of concrete. Under impact loading, rubberized concrete has better failure modes. Figure 12 displays the failure modes of all types of specimens at air pressure of $0.3,0.45$ and $0.75 \mathrm{MPa}$. Cracks are generated in all types of specimens at air pressure of $0.3 \mathrm{MPa}$. As shown in figure $12 \mathrm{a}$, plain concrete presents a brittle failure mode where the specimen separates into two halves, while rubberized concrete presents a ductile failure mode without dramatic fracture. It can be observed from figure $12 \mathrm{~b}$ that plain concrete specimens subjected to impact air pressure of $0.45 \mathrm{MPa}$ become debris, while rubberized concrete specimens maintain integrity after

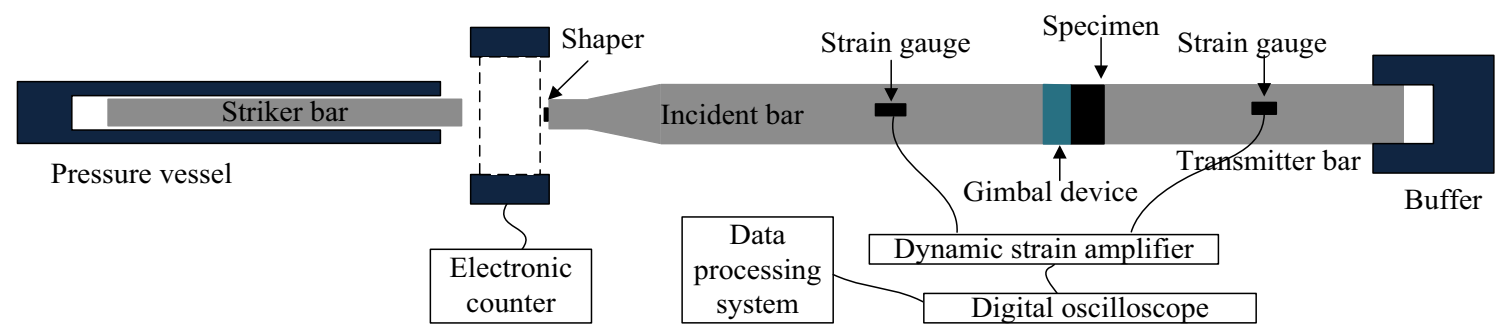

Figure 8. Dynamic compressive test.

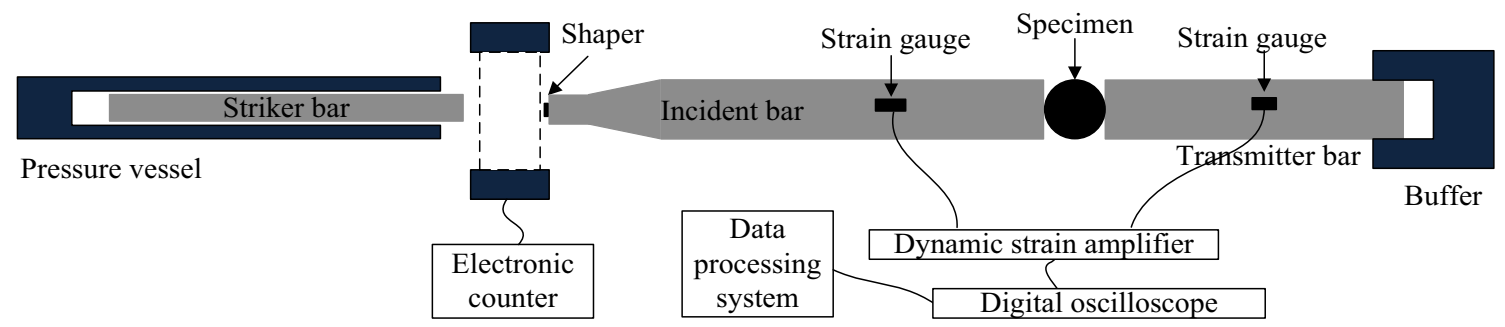

Figure 9. Dynamic splitting tensile test. 


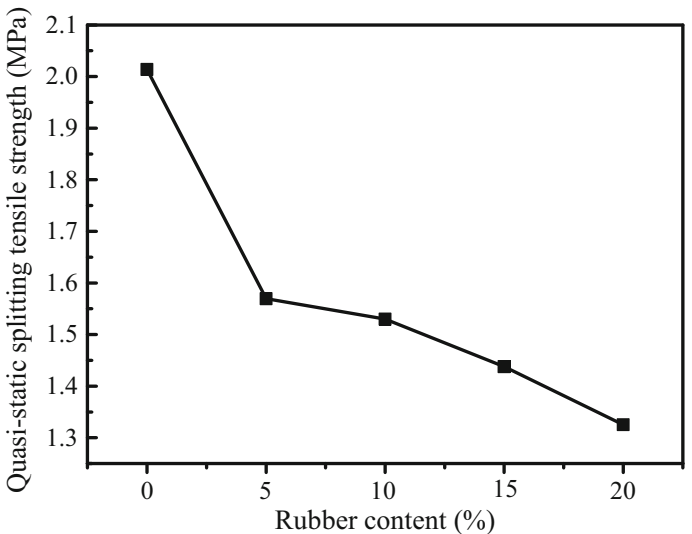

Figure 11. Quasi-static splitting tensile strength of specimens with different rubber contents.

damage. Only rubberized concrete with $20 \%$ rubber replacements has a severe damage due to its low strength. This indicates that rubberized concrete has higher deformation capacity. This can be understandable since rubber particles can form large deformation in short time when stress is transferred to rubber particles. This prevents the crack from rapid development and transfixion [31].

All specimens at air pressure of 0.6 and $0.75 \mathrm{MPa}$ became debris. Figure 12c shows the failure patterns of specimens at air pressures of $0.75 \mathrm{MPa}$. The fragments of rubberized concrete are sticky with smaller pieces of debris compared with clean fragments of plain concrete. This phenomenon reflects the development patterns of internal cracks of rubberized concrete. When the plain concrete was subjected to air pressures of $0.75 \mathrm{MPa}$, due to over-quick stress growth, initial cracks rapidly developed and penetrated through cement paste and coarse aggregates until fragments were generated [32]. However, large transverse deformation of rubber particles results in transverse force, which leads to more transverse cracks. Due to the high modulus of elasticity of rubber particles, rubber particles and debris generated by the transverse cracks are not entirely separate from each other after energy release. This is why the fragments of rubberized concrete are sticky with smaller pieces of debris.

3.2b Stress-strain curves of dynamic compression tests: Figure 13 illustrates the stress-strain curves of all types of concrete under impact loading with different air pressures. Since the impact velocities (see figure 13) of the striker bar at the same air pressure presented a very low degree of dispersion, the assumption that concrete is subjected to the same impact force at the same air pressure is applied in this paper. The results indicate that incorporation of rubber particles reduces the dynamic compressive strength. In addition, the peak strain increases significantly when air pressure is below $0.75 \mathrm{MPa}$, and rubberized concrete shows a high deformation capacity. As observed in figure 14, peak strain increases systematically with rubber content when air pressure is below $0.75 \mathrm{MPa}$, and changes slightly with rubber content at $0.75 \mathrm{MPa}$. Besides, the post-peak response of rubberized concrete is longer than that of plain concrete, which implies more energy dissipation.

3.2c Dynamic compressive strength: From figure 15 the impact of air pressure on dynamic compressive strength can (a) $0.3 \mathrm{MPa}$
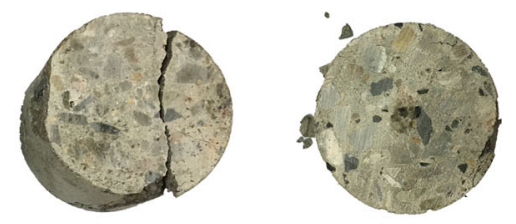

(b) $0.45 \mathrm{MPa}$

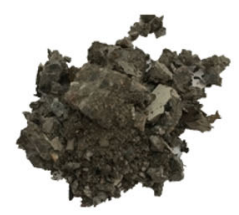

(c) $0.75 \mathrm{MPa}$

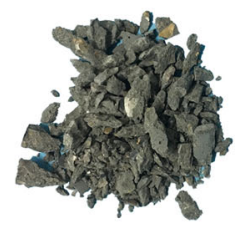

PC
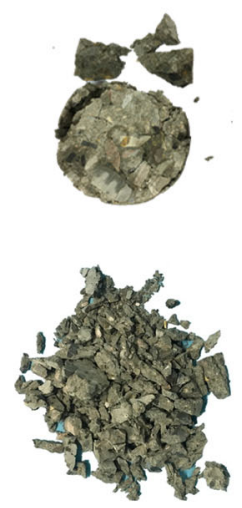

RC5
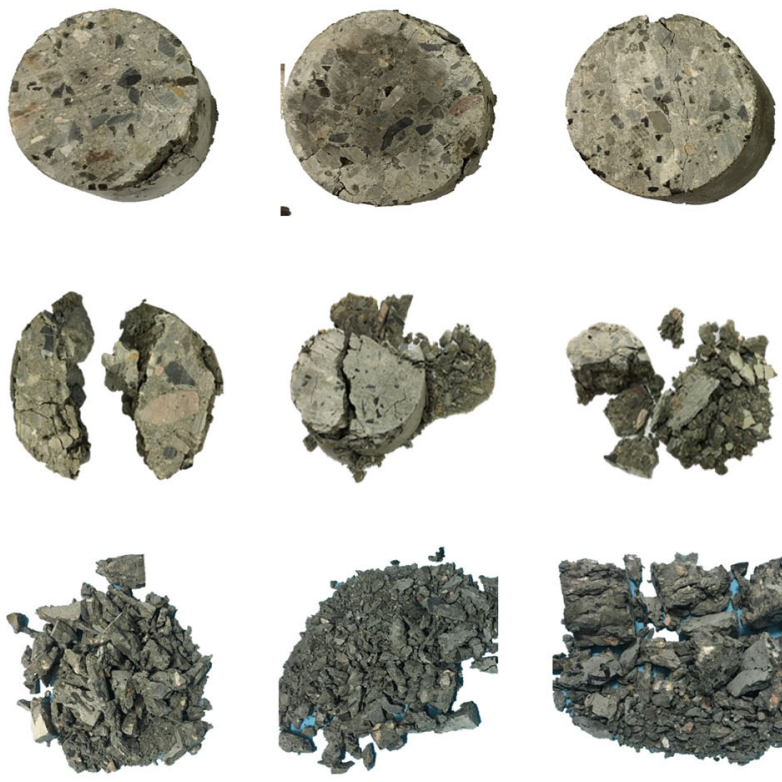

$\mathrm{RC} 10$
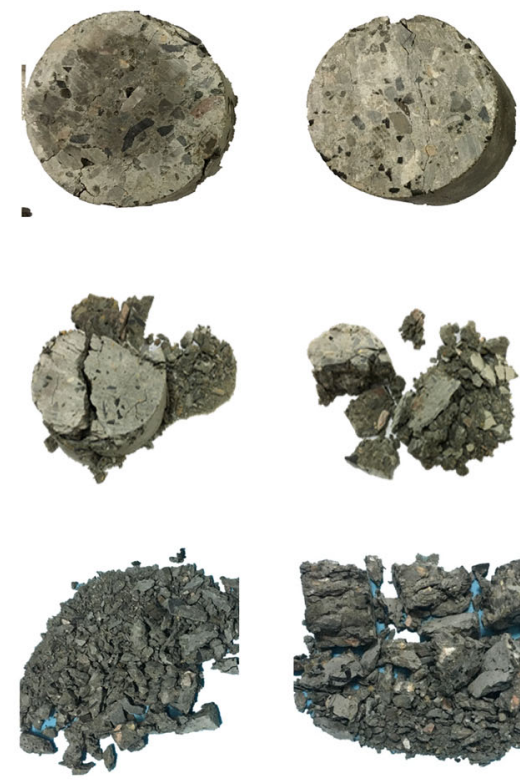

RC15

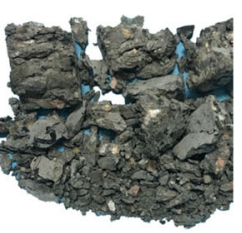

RC20

Figure 12. Failure modes of specimens under air pressure of $0.3,0.45$ and $0.75 \mathrm{MPa}$. (a) $0.3 \mathrm{MPa}$. (b) $0.45 \mathrm{MPa}$. (c) $0.75 \mathrm{MPa}$. 

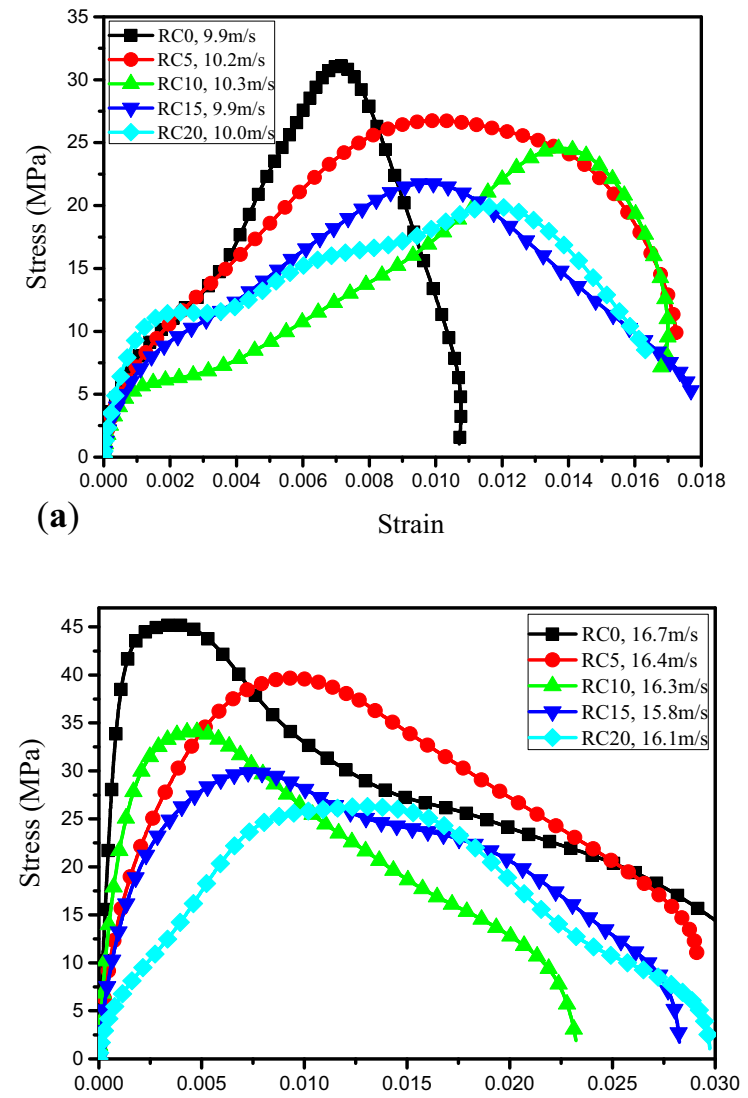

(c)

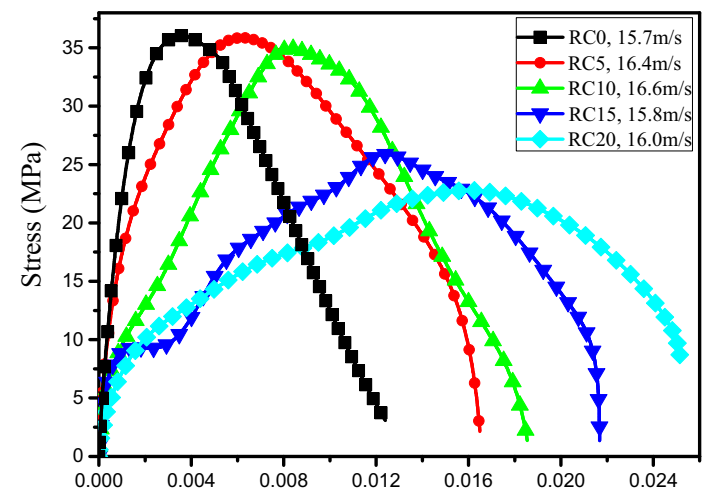

(b)

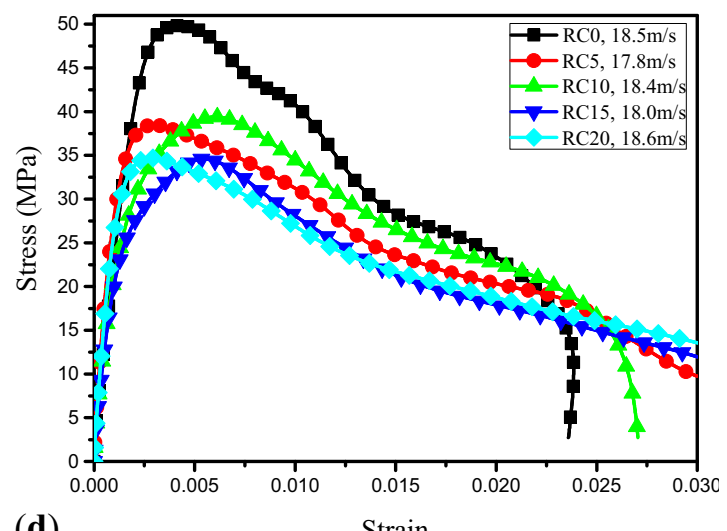

(d)

Figure 13. Stress-strain curves of rubberized concrete under different air pressures. (a) $0.3 \mathrm{MPa}$. (b) $0.45 \mathrm{MPa}$. (c) $0.6 \mathrm{MPa}$. (d) $0.75 \mathrm{MPa}$.

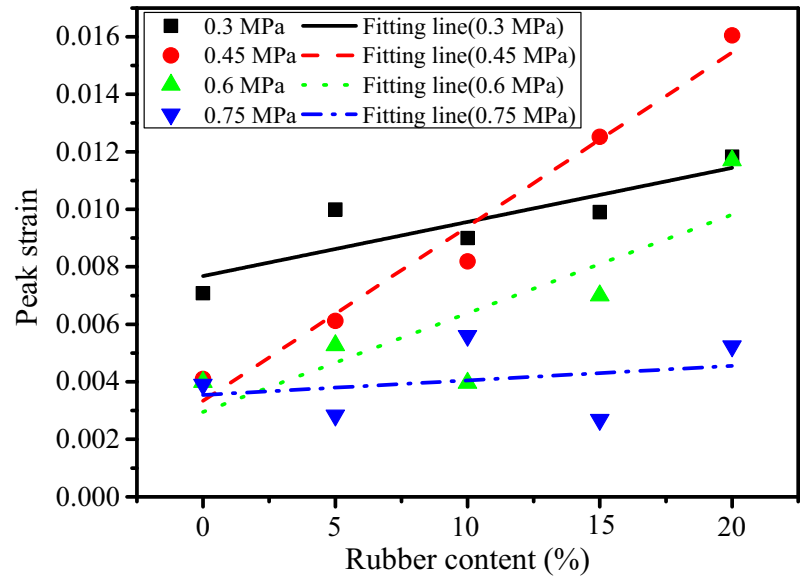

Figure 14. The relationship between peak strain and rubber content.

be seen. Results illustrate that rubberized concrete has a strength enhancement when air pressure rises.

Figure 16 shows the correlation between dynamic compressive strength and rubber content. It is observed that the decrease law of dynamic compressive strength is similar to that quasi-static compressive strength except for the response at air pressure of $0.45 \mathrm{MPa}$. The mechanisms responsible for the deterioration of dynamic compressive strength are also the same as that of the quasi-static compressive strength.

3.2d Dynamic increase factor (DIF) of compressive strength: It has been widely agreed that concrete strength can exhibit an enhancement trend with strain rates. Therefore, the dynamic increase factor $(D I F)$ was utilized to evaluate the strain rate sensitivity, which was defined as the ratio of dynamic strength values to quasi-static strength values [33]. Table 4 presents the average strain rate and the average values of $D I F$ of dynamic compressive strength of rubberized concrete. It can be observed that $D I F$ values of rubber concrete are always higher than that of plain concrete when rubber replacement is below 20\%, which increase steadily with rubber content. However, DIF values decline when rubber replacement is $20 \%$. It demonstrates that the incorporation of rubber particles increases the strain rate sensitivity of concrete.

Previous studies have revealed that there is a linear correlation between DIF and logarithm of strain rates [34]. Figure 17 shows the various laws of $D I F$ with $\lg (\dot{\varepsilon})$. The 


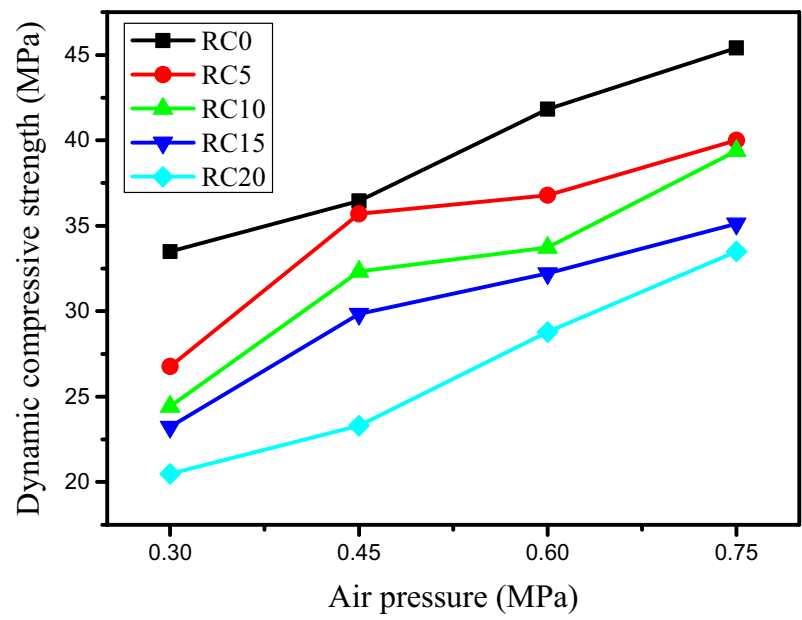

Figure 15. Dynamic compressive strength of specimens under different air pressures.

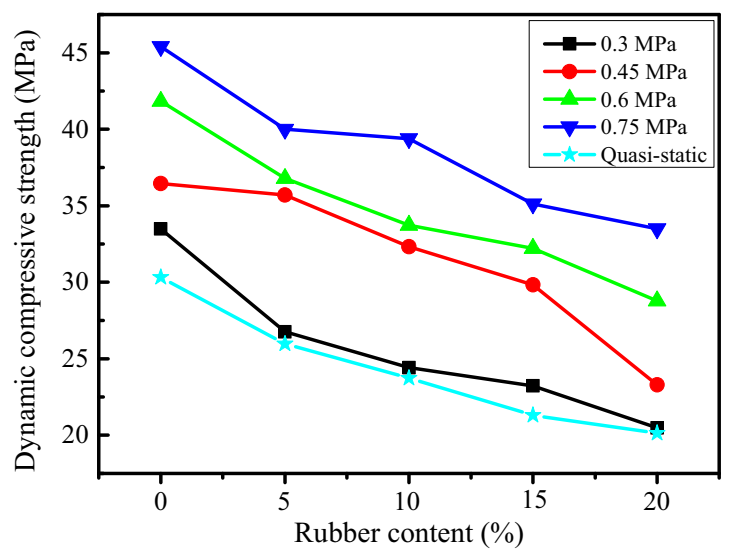

Figure 16. Dynamic compressive strength of specimens with different rubber content.

data were linearly fitted, and results reveal that the growth rates of $D I F$ increased with rubber content. The relationship between $D I F$ and $\lg (\dot{\varepsilon})$ can be expressed as

$$
D I F=\mathrm{a} \cdot \lg (\dot{\varepsilon})+b
$$

Similar results were found in previous experiments $[4,17,19]$, as shown in figure 18 . This can be attributed to the weakening effect of rubber particles on stress concentration at high strain rates. The inertia effect of lateral deformation is restrained, which approximately is generation of confining pressure. This is the reason why rubberized concrete has higher strain rate sensitivity.

3.2e Specific energy absorption: As an important index at the point of energy, specific energy absorption has been widely adopted to evaluate the impact toughness of cement-based materials, which is defined as energy absorption capability per unit volume [35]. Energy absorption capability can be determined utilizing the following formula:

$$
W=A_{b} C_{b} E_{b} \int_{0}^{t}\left[\varepsilon_{I}^{2}(t)-\varepsilon_{r}^{2}(t)-\varepsilon_{t}^{2}(t)\right] d t
$$

where $A_{b}, C_{b}$ and $E_{b}$ denote, respectively, the cross-sectional area, longitudinal wave velocity and elastic modulus of the bars, $\varepsilon_{i}(t), \varepsilon_{\mathrm{r}}(t)$ and $\varepsilon_{\mathrm{t}}(t)$ denote, respectively, the strains generated by incident wave, reflected wave and transmitted wave, respectively, and $t$ denotes the duration of waves.

Specific energy absorption is expressed as

$$
S E A=\frac{W}{V_{s}}
$$

where $V_{s}$ denotes the volume of specimens.

Figure 19 illustrates that specific energy absorption increases with air pressure to a linear approximation. This can be attributed to the damage levels increase with air pressure.

In addition, from figure 20 it can be observed that specific energy absorption increases slightly with rubber content at different impact air pressures. The results demonstrate that rubberized concrete with $15 \%$ rubber replacement has the best impact toughness in this study.

Although rubberized concrete has a lower strength, its high toughness results in larger peak strain and longer postpeak response. This can explain the increase of specific energy absorption of rubberized concrete. However, at $20 \%$ rubber replacement, rubberized concrete is too weak to

\begin{tabular}{|c|c|c|c|c|c|c|c|c|c|}
\hline \multirow[b]{2}{*}{ Serial } & \multirow[b]{2}{*}{$\begin{array}{l}\text { Quasi-static compressive strength } \\
(\mathrm{MPa})\end{array}$} & \multicolumn{2}{|c|}{$0.3 \mathrm{MPa}$} & \multicolumn{2}{|c|}{$0.45 \mathrm{MPa}$} & \multicolumn{2}{|c|}{$0.6 \mathrm{MPa}$} & \multicolumn{2}{|c|}{$0.75 \mathrm{MPa}$} \\
\hline & & $\begin{array}{l}\text { Strain rate } \\
\qquad\left(\mathrm{s}^{-1}\right)\end{array}$ & $D I F$ & $\begin{array}{l}\text { Strain rate } \\
\qquad\left(\mathrm{s}^{-1}\right)\end{array}$ & $D I F$ & $\begin{array}{l}\text { Strain rate } \\
\qquad\left(\mathrm{s}^{-1}\right)\end{array}$ & $D I F$ & $\begin{array}{l}\text { Strain rate } \\
\qquad\left(\mathrm{s}^{-1}\right)\end{array}$ & $D I F$ \\
\hline $\mathrm{RC} 0$ & 30.33 & 73.85 & 1.03 & 86.44 & 1.14 & 115.37 & 1.38 & 128.30 & 1.50 \\
\hline RC5 & 25.98 & 71.51 & 1.03 & 88.04 & 1.29 & 119.93 & 1.42 & 127.77 & 1.54 \\
\hline RC10 & 23.74 & 73.26 & 1.03 & 89.99 & 1.36 & 111.28 & 1.42 & 121.05 & 1.66 \\
\hline RC15 & 21.30 & 68.81 & 1.09 & 83.15 & 1.58 & 104.40 & 1.65 & 118.31 & 1.97 \\
\hline $\mathrm{RC} 20$ & 20.13 & 75.34 & 1.02 & 88.97 & 1.16 & 101.43 & 1.43 & 115.89 & 1.66 \\
\hline
\end{tabular}
generate longer post-peak response.

Table 4. The relation of average DIF and average strain rates. 


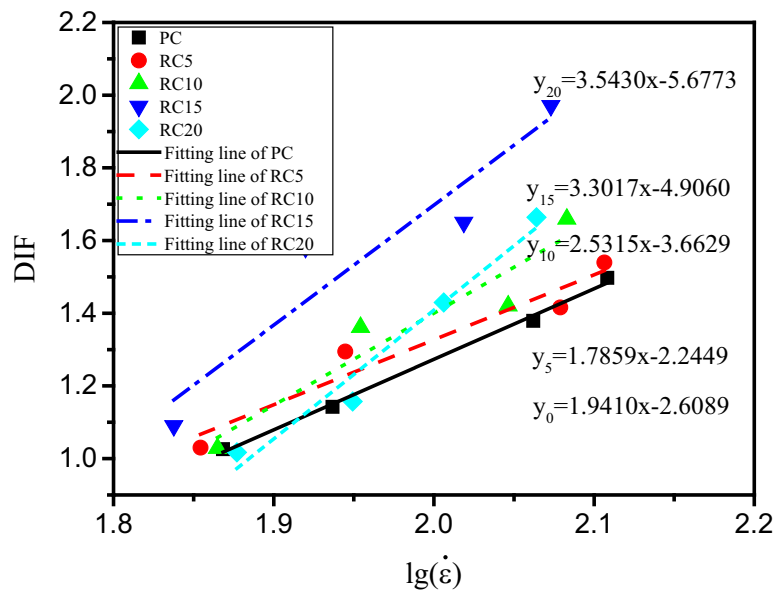

Figure 17. The relationship between $D I F$ and $\lg (\dot{\varepsilon})$ in this study.

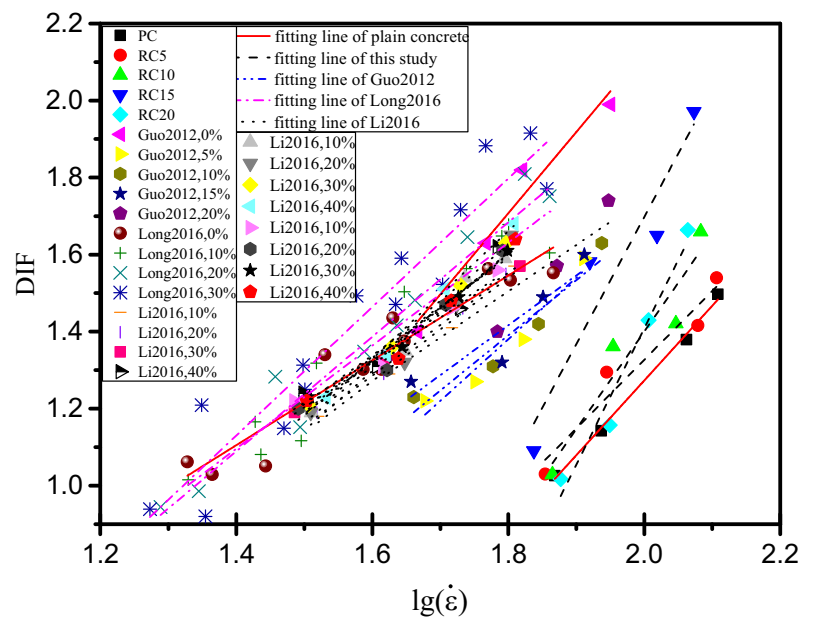

Figure 18. The relationship between $D I F$ and $\lg (\dot{\varepsilon})$.

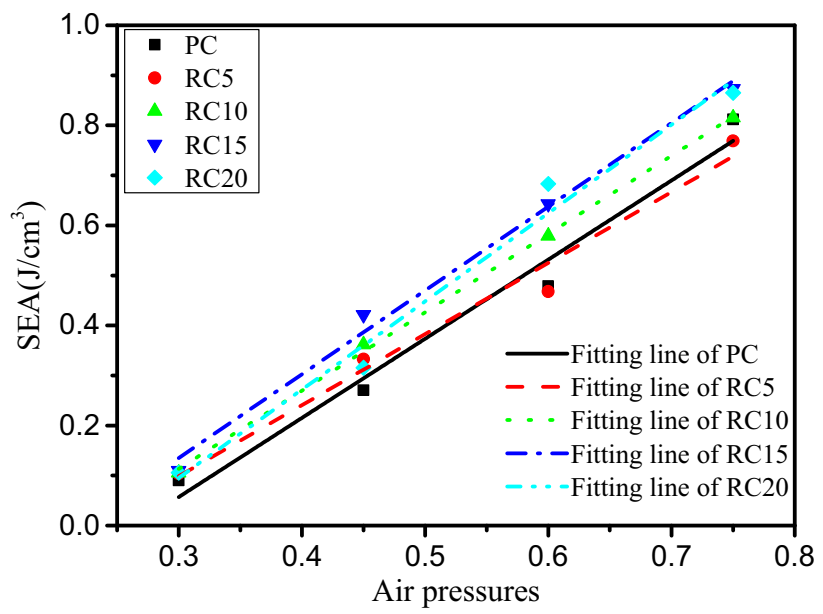

Figure 19. Specific energy absorption of specimens under different air pressures.

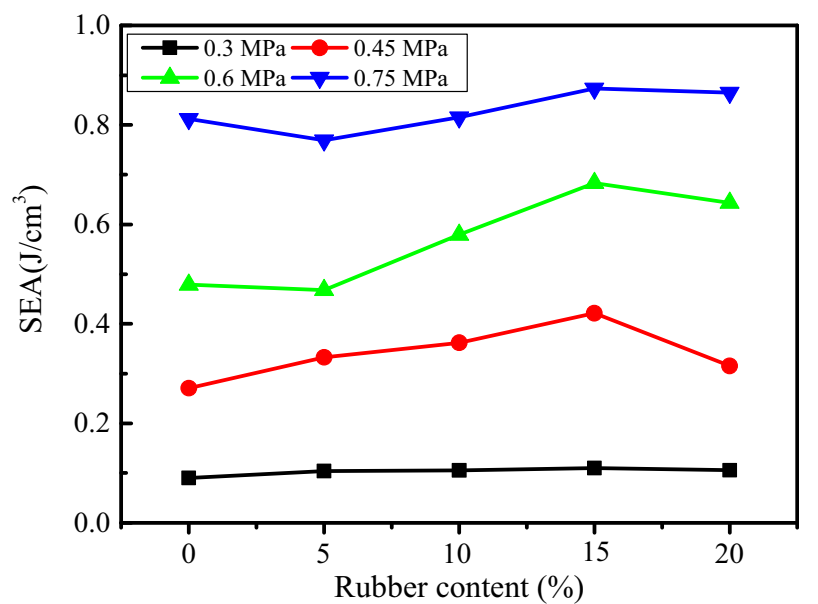

Figure 20. Specific energy absorption of specimens with different rubber contents.

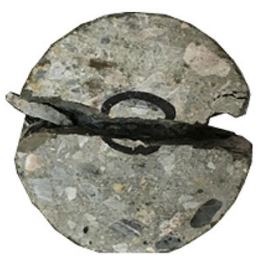

(a) $\mathrm{PC}$

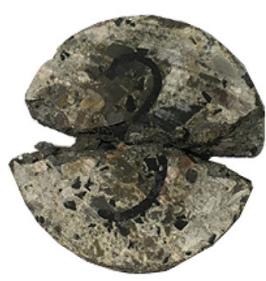

(d) $\mathrm{RC} 15$

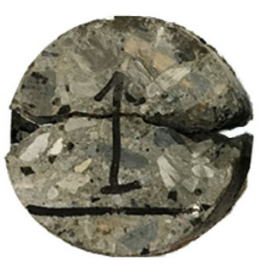

(b) RC5

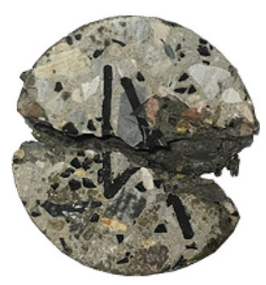

(e) RC20

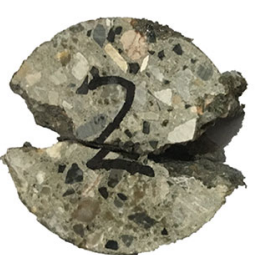

(c) $\mathrm{RC} 10$
Figure 21. Failure modes of rubberized concrete in the dynamic splitting tensile tests. (a) PC. (b) RC5. (c) RC10. (d) RC15. (e) RC20.

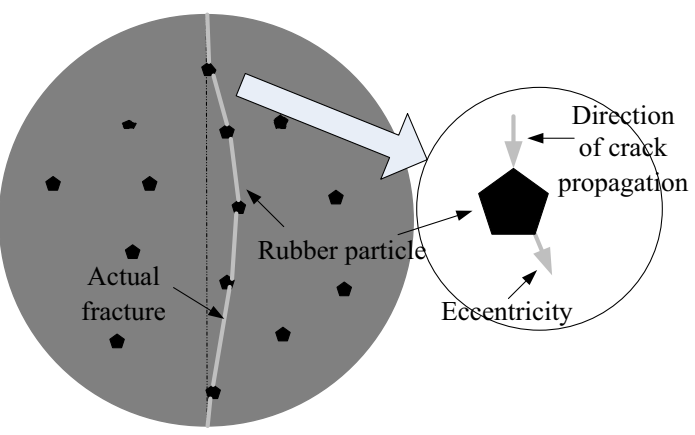

Figure 22. The eccentricity effect of rubber particles. 


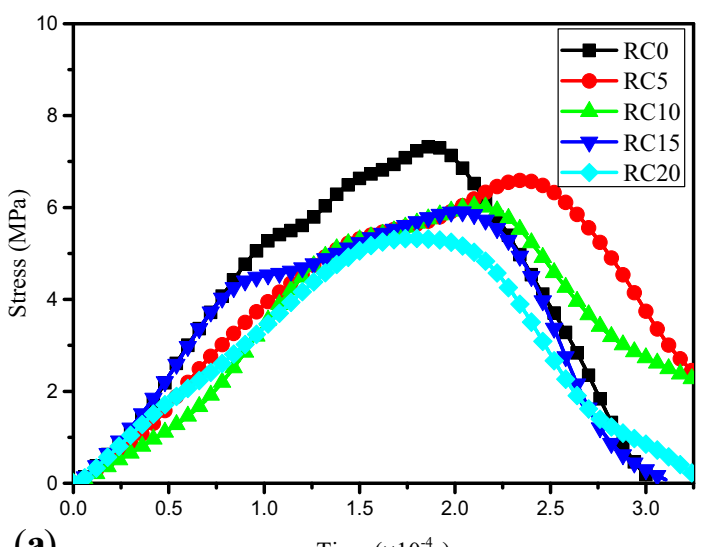

(a)

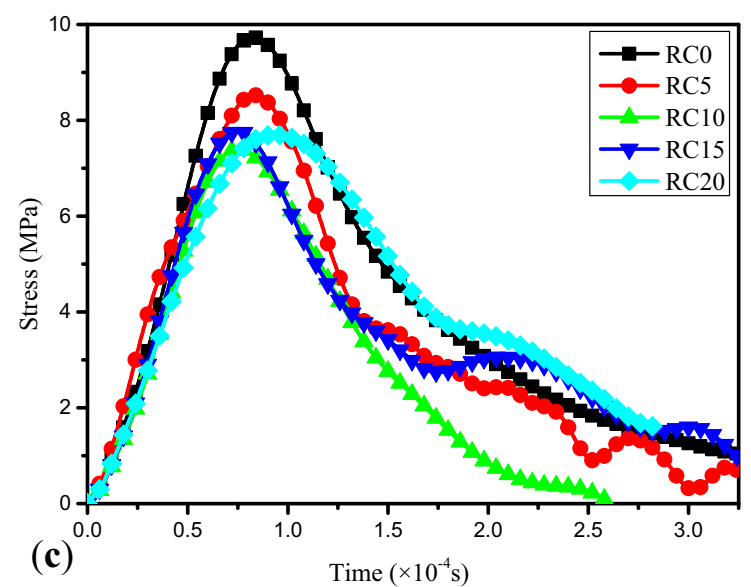

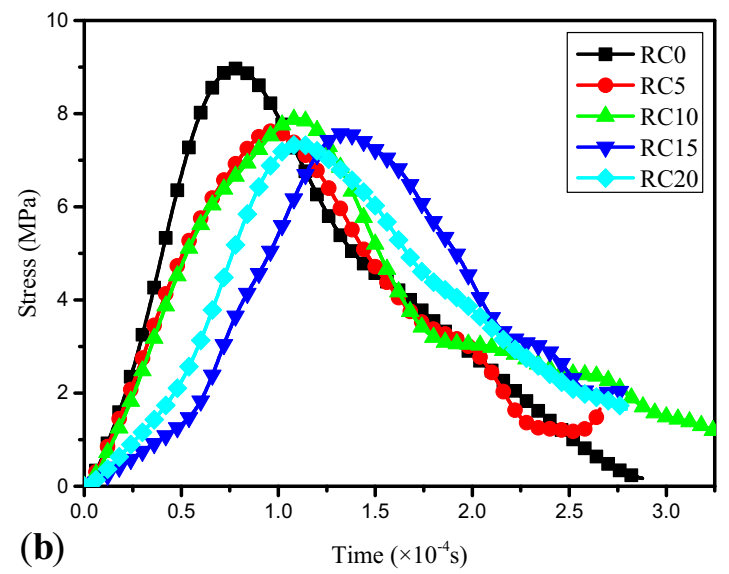

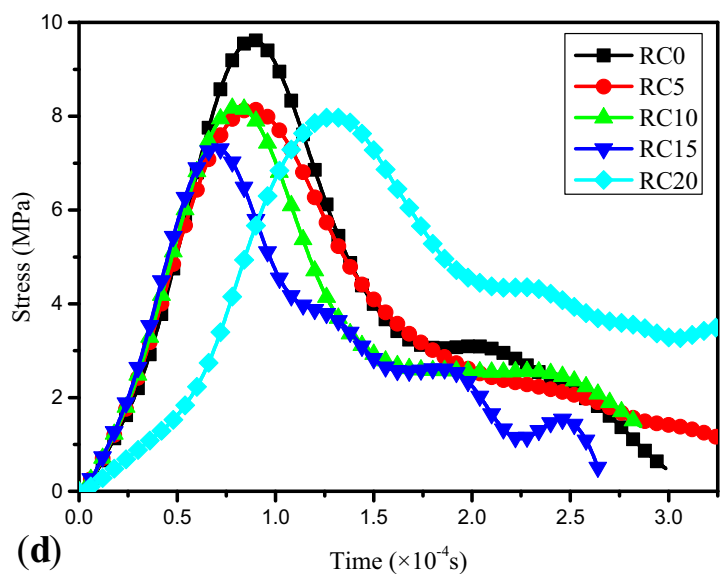

Figure 23. Stress-time history curves of rubberized concrete in the dynamic splitting tensile tests. (a) $0.15 \mathrm{MPa}$. (b) $0.3 \mathrm{MPa}$. (c) $0.45 \mathrm{MPa}$. (d) $0.6 \mathrm{MPa}$

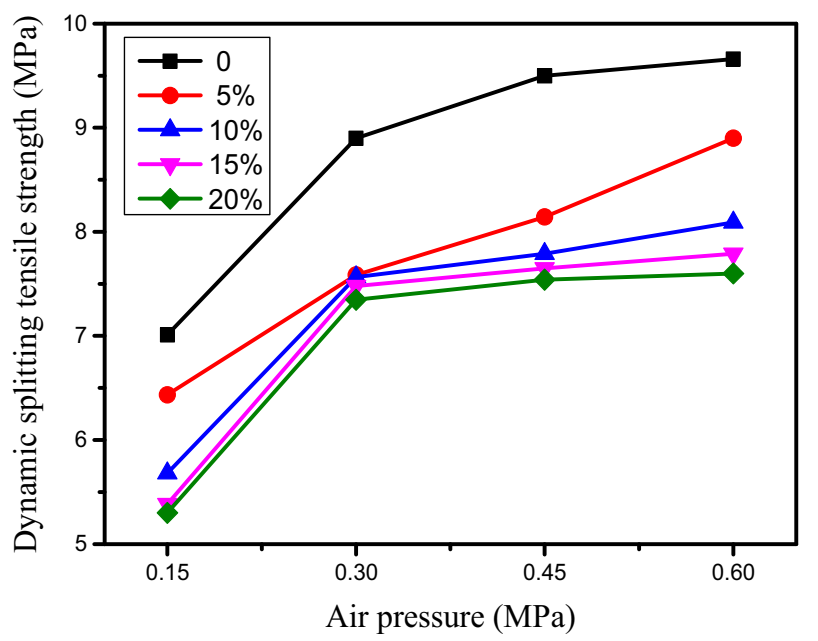

Figure 24. Dynamic splitting tensile strength of specimens under different air pressures.

\subsection{Dynamic splitting tensile tests}

3.3a Failure modes in the dynamic splitting tensile tests: As an example, figure 21 shows the failure modes of rubberized concrete at impact air pressure of $0.3 \mathrm{MPa}$. It is observed that the concrete specimens have a crushing zone at the radial loading end, and the area of the crushed zone increases with rubber content. This is due to lower strength of rubberized concrete.

Figure 21 also shows that the cracks in rubberized concrete are not straight and smooth, while the cracks propagate straight along the central axis in plain concrete. It could be interpreted by the eccentricity effect of rubber particles on propagation of cracks, as shown in figure 22 . Under impact loading, crack can even break through the aggregate in plain concrete in a short time [36]. However, crack propagation on the central axis of concrete as the dominant failure mechanism is prevented by rubber particles [37, 38]. Large transverse deformations of rubber particles turn the propagation to other weak ITZ or particle corner, which has a serious stress concentration.

3.3b Stress-time history curves in the dynamic splitting tensile tests: Figure 23 shows the stress-time history curves of rubberized concrete in the dynamic splitting tensile tests. It can be observed that rubberized concrete is always lower than plain concrete for the dynamic splitting tensile 


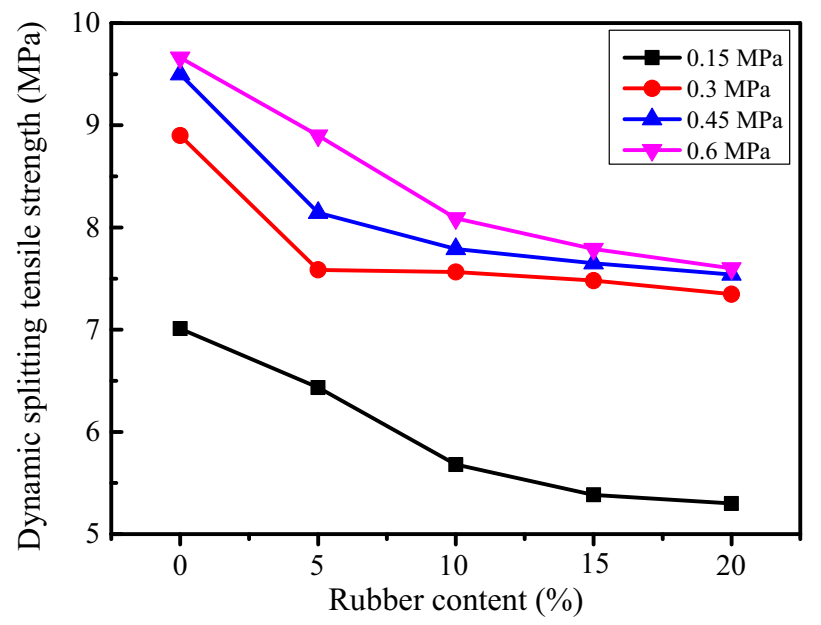

Figure 25. Dynamic splitting tensile strength of specimens with different rubber contents.

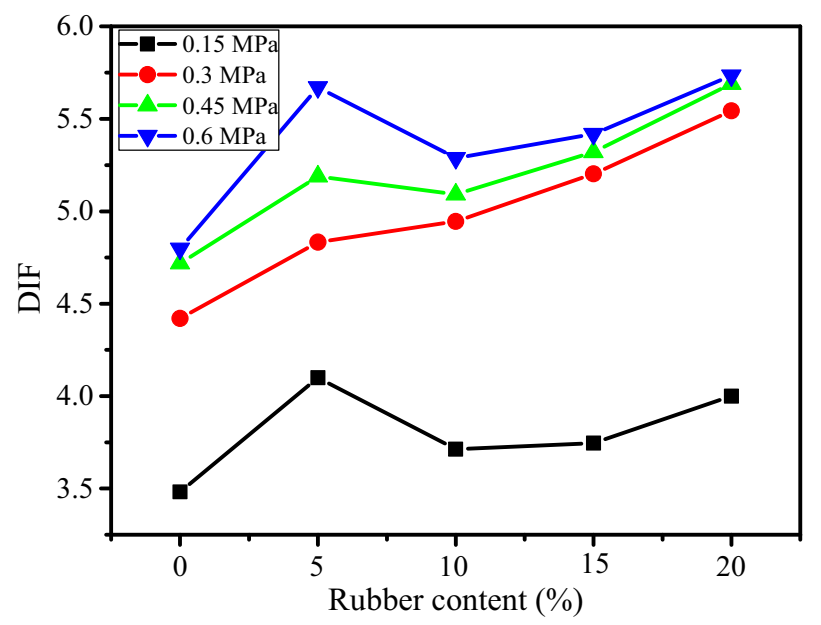

Figure 26. Correlation between $D I F$ of splitting tensile strength and rubber content.

Table 5. The ratios of dynamic compressive-tensile strength.

\begin{tabular}{|c|c|c|c|c|c|}
\hline Serial & $\begin{array}{l}\text { Quasi- } \\
\text { static } \\
(\mathrm{MPa})\end{array}$ & $0.15 \mathrm{MPa}$ & $0.30 \mathrm{MPa}$ & $0.45 \mathrm{MPa}$ & $0.6 \mathrm{MPa}$ \\
\hline $\mathrm{RC} 0$ & 15.06 & 4.44 & 3.89 & 4.40 & 4.70 \\
\hline RC5 & 16.55 & 4.16 & 4.43 & 4.52 & 4.49 \\
\hline $\mathrm{RC} 10$ & 15.51 & 4.30 & 4.27 & 4.33 & 4.87 \\
\hline $\mathrm{RC} 15$ & 14.82 & 4.31 & 4.50 & 4.59 & 5.39 \\
\hline $\mathrm{RC} 20$ & 15.19 & 3.86 & 3.17 & 3.82 & 4.41 \\
\hline
\end{tabular}

strength. However, the peak strength of rubberized concrete with different rubber contents does not have significant difference. The change law of the dynamic splitting tensile strength is consistent with that of quasi-static splitting tensile strength. It could be explained by the same reasons affecting quasi-static splitting tensile strength. 3.3c Dynamic splitting tensile strength: From figure 24 it can be observed that dynamic splitting tensile strength has a corresponding increase when air pressure rises. Unlike dynamic compressive strength, strain rate sensitivity of rubberized concrete in the dynamic splitting tensile tests is no longer significant at $10 \%, 15 \%$ and $20 \%$ rubber replacement.

Figure 25 illustrates the correlation between dynamic splitting tensile strength and rubber content. There is a sharp decline in the dynamic splitting tensile strength of rubberized concrete when rubber particles at 5\% replacement are added, which is similar with quasi-static splitting tensile strength tests. When rubber content continues to increase, the loss in the dynamic splitting tensile strength is no longer dramatic. The strength loss at 5\% rubber replacement at different air pressures was obtained as $8.23 \%, 14.78 \%, 14.28 \%$ and $7.87 \%$, all of which fall below the quasi-static strength loss of $22.06 \%$. The strength loss at $20 \%$ rubber replacement at different air pressures was obtained as $24.39 \%, 17.45 \%, 20.63 \%$ and $21.33 \%$, all of which fall below the quasi-static strength loss of $34.18 \%$. This could be explained by the fact that stress concentration phenomenon is more serious at high stain rate. Thus, the effect of rubber particles on preventing stress concentration is significant. This reveals that the loss of dynamic splitting tensile strength of rubberized concrete is less than that of quasi-static splitting tensile strength.

3.3d Dynamic increase factor (DIF) of splitting tensile strength: DIF of splitting tensile strength increases generally with rubber replacement, as illustrated in figure 26, where DIF values of concrete with 5\% rubber replacement are outstanding. It can be explained by the considerable reduction of quasi-static splitting tensile strength when 5\% rubber particles are added. It illustrates that concrete with $5 \%$ rubber content has stronger strain rate sensitivity to splitting tension. As revealed in 3.3a, this could be mainly explained by the negative effect of rubber particles on crack propagation.

\subsection{The relationship of dynamic compressive- tensile strength}

There is no clear tendency in relationship between the ratios of dynamic compressive-tensile strength and rubber content, as shown in table 5. The ratios of dynamic compressive-tensile strength are between 3.82 and 5.39, which are far below those in quasi-static tests.

\section{Conclusions}

The dynamic compressive and splitting tensile properties of rubberized concrete with different rubber contents were investigated using SHPB in this study. From the discussion, five conclusions were reached. 
(1) Failure modes of rubberized concrete in the dynamic compression tests are more severe when strain rates increase. The incorporation of rubber particles can improve compressive failure modes. In the dynamic splitting tensile tests, the cracks of rubberized concrete are not straight and smooth due to the effect of rubberized particles.

(2) Like quasi-static tests, there is a significant decrease in both dynamic compressive and splitting tensile strength of rubberized concrete with increasing rubber content at different strain rates. However, dynamic tensile strength is relatively insensitive to increase in rubber content compared with the dynamic compressive strength.

(3) Rubberized concrete shows a stronger strain rate sensitivity phenomenon whether in the dynamic compressive or splitting tensile tests. DIF values increase generally with rubber content. Combining with the analyses of previous studies, it can be concluded that growth rates of DIF increase with rubber content in the dynamic compressive tests.

(4) In dynamic compressive tests, peak strain dramatically increases with the increase of rubber content. The analysis of specific energy absorption further explains that rubberized concrete has a better impact toughness. The data illustrate that rubberized concrete with $15 \%$ rubber replacement has the best impact toughness in this study.

(5) There is no clear tendency in the change of the ratios of dynamic compressive-tensile strength with rubber content. The ratios of dynamic compressive-tensile strength are between 3.82 and 5.39, which are far below that in quasi-static.

\section{Acknowledgements}

The research is based upon the work supported by Open Research Fund Program of State Key Laboratory of Water Resources and Hydropower Engineering Science (Grant No. 2016SGG01), the National Natural Science Foundation of China (Grant No. 51509085), Natural Science Foundation of Jiangsu Province (Grant No. BK20150820) and the Priority Academic Program Development of Jiangsu Higher Education Institutions.

\section{References}

[1] Najim K B and Hall M R 2010 A review of the fresh/hardened properties and applications for plain-(PRC) and selfcompacting rubberised concrete (SCRC). Constr. Build. Mater. 24(11): 2043-2051

[2] Najim K B and Hall M R 2012 Mechanical and dynamic properties of self-compacting crumb rubber modified concrete. Constr. Build. Mater. 27(1): 521-530
[3] Thomas B S and Gupta R C 2016 A comprehensive review on the applications of waste tire rubber in cement concrete. Renew. Sust. Energ. Rev. 54: 1323-1333

[4] Li L J, Tu G, Lan C and Liu F 2016 Mechanical characterization of waste-rubber-modified recycled-aggregate concrete. J. Cleaner Prod. 124: 325-338

[5] Su H L, Yang J, Ling T C and Ghataora G S 2015 Properties of concrete prepared with waste tyre rubber particles of uniform and varying sizes. J. Cleaner Prod. 91(71): 288-296

[6] Son K S, Hajirasouliha I and Pilakoutas K 2011 Strength and deformability of waste tyre rubber-filled reinforced concrete columns. Constr. Build. Mater. 25(1): 218-226

[7] Wang C, Zhang Y and Ma A 2011 Investigation into the fatigue damage process of rubberized concrete and plain concrete by AE analysis. J. Mater. Civil Eng. 23(7): 953-960

[8] Mohammadi I and Khabbaz H 2015 Shrinkage performance of Crumb Rubber Concrete (CRC) prepared by water-soaking treatment method for rigid pavements. Cement Concr. Compos. 62(4): 106-116

[9] Bravo M and Brito J D 2012 Concrete made with used tyre aggregate: durability-related performance. J. Cleaner Prod. 25(4): 42-50

[10] Richardson A, Coventry K, Edmondson V and Dias E 2016 Crumb rubber used in concrete to provide freeze-thaw protection (optimal particle size). J. Cleaner Prod. 112: 599-606

[11] Shu X and Huang B 2014 Recycling of waste tire rubber in asphalt and Portland cement concrete: an overview. Constr. Build. Mater. 67: 217-224

[12] Atahan A O and Yücel A Ö 2012 Crumb rubber in concrete: static and dynamic evaluation. Constr. Build. Mater. 36(4): 617-622

[13] Al-Tayeb M M, Bakar B A, Akil H M and Ismail H 2013a Performance of rubberized and hybrid rubberized concrete structures under static and impact load conditions. Exp. Mech. 53(3): 377-384

[14] Al-Tayeb M M, Bakar B A, Ismail H and Akil H M 2013b Effect of partial replacement of sand by recycled fine crumb rubber on the performance of hybrid rubberized-normal concrete under impact load: experiment and simulation. $J$. Cleaner Prod. 59: 284-289

[15] Moustafa A and ElGawady M A 2017 Dynamic properties of high strength rubberized concrete. ACI Spec. Publ. 314: $1-22$

[16] Gupta T, Tiwari A, Siddique S, Sharma R K and Chaudhary S 2017 Response assessment under dynamic loading and microstructural investigations of rubberized concrete. $J$. Mater. Civil Eng. 29(8): 4017062

[17] Guo Y, Liu F, Chen G and Liu F 2012 Experimental investigation on impact resistance of rubberized concrete. $J$. Build. Mater. (in Chinese) 15(1): 139-144

[18] Liu F, Meng L, Chen G X and Li L J 2015 Dynamic mechanical behaviour of recycled crumb rubber concrete materials subjected to repeated impact. Mater. Res. Innov. 19(S8): S8-S496

[19] Long G C, Li N, Xue Y and Xie Y J 2016 Mechanical properties of self-compacting concrete incorporating rubber particles under impact load. J. Chin. Ceram. Soc. 44(8): $1081-1090$

[20] Mohammadi I, Khabbaz H and Vessalas K 2014 In-depth assessment of Crumb Rubber Concrete (CRC) prepared by 
water-soaking treatment method for rigid pavements. Constr. Build. Mater. 71: 456-471

[21] Güneyisi E, Gesoğlu M and Özturan T 2004 Properties of rubberized concretes containing silica fume. Cement Concr. Res. 34(12): 2309-2317

[22] ASTM C39/C39M-17b 2017 Standard test method for compressive strength of cylindrical concrete specimens. ASTM International, West Conshohocken, PA

[23] ASTM C496/C496M-11 2004 Standard test method for splitting tensile strength of cylindrical concrete specimens. ASTM International, West Conshohocken, PA

[24] Chen X D, Wu S X and Zhou J K 2014 Quantification of dynamic tensile behavior of cement-based materials. Constr. Build. Mater. 51(51): 15-23

[25] Chen X D, Ge L M, Chen C and Xu L Y 2016 Influence of initial static splitting tensile loading on dynamic compressive strength of concrete cores under high strain rates. J. Perform. Constr. Facil. 30(6): 06016002

[26] Chen X D, Ge L M, Zhou J K and Wu S X 2015 Experimental study on split Hopkinson pressure bar pulse-shaping techniques for concrete. J. Mater. Civil Eng. 28(5): 4015196

[27] Zhou J K, Chen X D, Wu L Q and Kan X W 2011 Influence of free water content on the compressive mechanical behaviour of cement mortar under high strain rate. Sadhana 36(3): 357

[28] Gupta T, Chaudhary S and Sharma R K 2016 Mechanical and durability properties of waste rubber fiber concrete with and without silica fume. J. Cleaner Prod. 112(1): 702-711

[29] Benazzouk A, Douzane O, Mezreb K and Quéneudec M 2006 Physico-mechanical properties of aerated cement composites containing shredded rubber waste. Cement Concr. Compos. 28(7): 650-657

[30] Girskas G and Nagrockiene D 2017 Crushed rubber waste impact of concrete basic properties. Constr. Build. Mater. 140: $36-42$

[31] Segre N, Joekes I, Galves A D and Rodrigues J A 2004 Rubber-mortar composites: effect of composition on properties. J. Mater. Sci. 39(10): 3319-3327

[32] Chen X D, Wu S X and Zhou J K 2013 Experimental and modeling study of dynamic mechanical properties of cement paste, mortar and concrete. Constr. Build. Mater. 47: $419-430$

[33] Zhou J K and Chen X D 2013 Stress-strain behavior and statistical continuous damage model of cement mortar under high strain rates. J. Mater. Civil Eng. 25(1): 120-130

[34] Li Q, Zhao X, Xu S and Gao X 2016 Influence of steel fiber on dynamic compressive behavior of hybrid fiber ultra high toughness cementitious composites at different strain rates. Constr. Build. Mater. 125: 490-500

[35] Fu Q, Xie Y J, Long G C, Niu D, Song H and Liu X 2017 Impact characterization and modelling of cement and asphalt mortar based on SHPB experiments. Int. J. Impact Eng. 106: 44-52

[36] Gomez J T, Shukla A and Sharma A 2001 Static and dynamic behavior of concrete and granite in tension with damage. Theor. Appl. Fract. Mech. 36(1): 37-49

[37] Chen X D, Ge L M, Zhou J K and Wu S X 2017 Dynamic Brazilian test of concrete using split Hopkinson pressure bar. Mater. Struct. 50(1): 1

[38] Eldin N N and Senouci A B 1993 Rubber-tire particles as concrete aggregate. J. Mater. Civil Eng. 5(4): 478-496 